\title{
Process Assessment of Heterogeneous Azeotropic Dividing-Wall Column for the Ethanol Dehydration with Cyclohexane as an Entrainer: Design and Control
}

\author{
Ye Li, ${ }^{1}$ Ming Xia, ${ }^{2}$ Weisong Li, ${ }^{1}$ Junwen Luo, ${ }^{1}$ Lei Zhong, ${ }^{1}$ Shanyuan Huang,,${ }^{1}$ Jian Ma, ${ }^{1}$ and \\ Chunjian $X u^{1, *}$ \\ ${ }^{1}$ State Key Laboratory of Chemical Engineering, Collaborative Innovation Center of Chemical \\ Science and Engineering, Chemical Engineering Research Center, and School of Chemical \\ Engineering and Technology, Tianjin University, Tianjin 300072, China \\ ${ }^{2}$ Institute of Coal Chemistry, Chinese Academy of Sciences, Taiyuan 030001, China \\ Tel: +86 022-27404440. Fax: +86 022-27404440. E-mail: cjxu@tju.edu.cn.
}

\begin{abstract}
Heterogeneous azeotropic dividing-wall column (ADWC) features significant reduction of capital investment and energy consumption. Conventional azeotropic distillation sequences can be thermally coupled into two types of configurations of ADWC, namely, the original ADWC with simple azeotropic/recovery section and the other with recovery section also severing as preconcentrator. The ADWC with combined recovery/preconcentrator section has been investigated on both steady design and dynamic controllability. However, the original ADWC has only been proved to be more energy saving than conventional azeotropic/recovery column sequence, not compared with conventional azeotropic/stripper column sequence. Furthermore, the dynamic performances of this ADWC are still unclear. Note that all the benefits of ADWC are reasonable only under good dynamic controllability. Thus, in this work, we develop a comparative study of optimal
\end{abstract}


design and dynamic performance of ADWC with two conventional sequences by demonstrating ethanol dehydration using cyclohexane as an entrainer. The results show that ADWC has significant capital investment reduction and energy saving than two conventional sequences. As two reboiler duties are still preserved in ADWC, it has comparable dynamic controllability with conventional azeotropic/recovery column sequence and superior dynamic controllability with conventional azeotropic/stripper column sequence.

Key words: heterogeneous azeotropic, dividing-wall column, ethanol dehydration, economic optimization, control strategy 


\section{Supporting Information}

To verify the accuracy of NRTL-RK model, the azeotropic points of experimental data are compared with the predictive data of NRTL-RK model. The NRTL Parameters for Cyclohexane/Ethanol/Water System in Aspen Plus is listed in Table 1. The comparison between the experiment data and the predicted data of NRTL-RK model in Aspen Plus is listed in Table 2. Obviously, the experiment data and the predicted data fit well.

Table 1. NRTL Parameters for Cycl./Ethanol/Water System In Aspen Plus

\begin{tabular}{cccc}
\hline Comp. i & Cycl.(1) & Cycl.(1) & Ethanol(2) \\
Comp. j & Ethanol(2) & Water(3) & Water(3) \\
\hline $\mathrm{a}_{\mathrm{ij}}$ & 1.6271 & -10.4585 & -0.8009 \\
$\mathrm{a}_{\mathrm{ji}}$ & -0.1560 & 13.1428 & 3.4578 \\
$\mathrm{~b}_{\mathrm{ij}}(\mathrm{K})$ & 214.0758 & 4954.8970 & 246.1800 \\
$\mathrm{~b}_{\mathrm{ji}}(\mathrm{K})$ & 459.8772 & -1066.9800 & -586.0810 \\
$\mathrm{c}_{\mathrm{ij}}$ & 0.4500 & 0.2000 & 0.3000 \\
\hline
\end{tabular}

Table 2. Comparison Between Predicted and Experimental Azeotropic Compositions and Bubble Points of Cycl./Ethanol/Water System (101.3 kPa)

\begin{tabular}{cc}
\hline \multicolumn{2}{c}{ Cycl./ethanol/water $(\mathrm{mol} / \mathrm{mol})$, bubble point $(\mathrm{K})$} \\
predicted values in Aspen Plus & $0.520 / 0.292 / 0.188,(335.54)^{1}$ \\
& $0.522 / 0.302 / 0.176,(335.7)^{2}$ \\
$0.5299 / 0.3203 / 0.1489,(335.21)$ & \\
$0.5614 / 0.4386 / 0,(337.75)$ & $0.561 / 0.439 / 0,(338.05)^{3}$ \\
$0.7012 / 0 / 0.2988,(342.41)$ & $0.700 / 0 / 0.300,(342.1)^{3}$ \\
$0 / 0.8921 / 0.1079,(351.29)$ & $0 / 0.904 / 0.096,(351.32)^{3}$ \\
\hline
\end{tabular}

Total annual cost (TAC) suggested by Douglas ${ }^{4}$ has been extensively employed in screening chemical process design. In this work, the total annual cost (TAC) including annual capital costs and operating costs, is used as the objective function to be minimized to screen the optimal design among feasible alternatives. It can be expressed by the equations 


$$
\mathrm{TAC}\left(10^{3} \$ \text { year }\right)=\mathrm{OC}+\mathrm{C}_{\mathrm{f}}+\left(i_{\mathrm{r}}+i_{\mathrm{m}}\right) \mathrm{CI}
$$

And CI $=$ installed column shell cost + installed column tray cost + installed heat exchanger cost, where OC is the operating cost, mostly utility consumption (stream, cooling water, and electricity); $\mathrm{C}_{\mathrm{f}}$ is the annual fixed cost, such as maintenance expense and wages; $\mathrm{CI}$ is the fixed capital investment; $i_{\mathrm{r}}$ is the fixed capital recovery rate applied to $\mathrm{CI}$; and $i_{\mathrm{m}}$ is the minimum acceptable rate of return on CI. $\mathrm{C}_{\mathrm{f}}$ is assumed to be $10 \%$ of $\mathrm{CI}$, and $i_{\mathrm{r}}+i_{\mathrm{m}}$ is assumed to be $20 \%$ of $\mathrm{CI}$ in this optimization. The details of both equations for determining OC and CI are mentioned in Douglas' book. ${ }^{4}$ The costs of the entrainer and entrainer makeup are not included in OC because they are much lower than the costs of the heat duties.

Major equipments for the processes in this study include the column vessel (including column internals) and heat exchangers (condensers and reboiler). Small items such as reflux drums, pumps, valves, and pipes are usually not considered because of their lower costs compared with the column vessel and heat exchangers. ${ }^{5}$ The "Tray Sizing" section in Aspen Plus is employed to size the column with a sieve plate. For all the columns of these three sequences, tray spacing $0.61 \mathrm{~m}$ is specified. The heat transfer areas for heat exchangers are calculated by using the overall heat transfer coefficient and a differential temperature driving force. Here, the overall heat transfer coefficients suggested by Luyben $^{5}$ are $0.852 \mathrm{~kW} /(\mathrm{K} \cdot \mathrm{m} 2)$ for the condensers and $0.568 \mathrm{~kW} /(\mathrm{K} \cdot \mathrm{m} 2)$ for the reboiler. The cost estimation program CAPCOST involved in Turton's book ${ }^{6}$ is used to estimate all the major equipment costs.

The utility consumption costs are calculated from the heat duties of the condensers and reboiler. Low-pressure steam with a pressure of $400 \mathrm{kPa}$ and cooling water with an inlet temperature of 305.4 $\mathrm{K}$ are assumed to be available in the plant. The utility prices taken from CAPCOST are listed in 
Table 3.

Table 3. Utility prices

\begin{tabular}{lc}
\hline utility & price $(\$ / \mathrm{GJ})$ \\
\hline low pressure steam $(400 \mathrm{kPa})$ & 13.28 \\
cooling water $(303.15 \mathrm{~K}$ to $318.15 \mathrm{~K})$ & 0.354 \\
electricity $(110 \mathrm{~V}-440 \mathrm{~V})$ & 16.8 \\
\hline
\end{tabular}

\section{References}

(1) Gomis, V.; Front, A.; Pedraza, R.; Saquete, M. D. Isobaric Vapor-Liquid and Vapor-Liquid-Liquid Equilibrium Data for the System Water Plus Ethanol Plus Cyclohexane. Fluid. Phase. Equilibr. 2005, $235,7$.

(2) Gmehling, Jürgen; Menke, Jochen; Krafczyk, Jörg; Fischer, Kai. Azeotropic Data. Wiley-VCH: Weinheim, Germany, 2004.

(3)Cheng N. L. Solvents Handbook. Chemical industry press: Beijing, China, 1994.

(4) Douglas, J. M. Conceptual Design of Chemical Processes; McGraw Hill: New York, 1998.

(5) Luyben, W. L. Distillation Design and Control Using Aspen Simulation; John Wiley \& Sons: New York, 2006.

(6) Turton, R.; Bailie, R. C.; Whiting, W. B.; Shaeiwitz, J. A. Analysis, Synthesis and Design of Chemical Processes; Prentice Hall: New York, 2009. 